\title{
Anatomia foliar de Melastomataceae do Cerrado do Estado de São Paulo ${ }^{1}$
}

\author{
CLAUDIA DOS REIS ${ }^{2,3}$, ANGELA C. BIERAS ${ }^{2}$ e MARIA DAS GRAÇAS SAJO ${ }^{2}$
}

(recebido: 7 de outubro de 2004; aceito: 31 de março de 2005)

\begin{abstract}
Leaf anatomy of Melastomataceae from the Cerrado of São Paulo State). We studied the leaf of 22 species of Melastomataceae (tribe Miconieae, Tibouchinieae e Microlicieae) from the cerrado of São Paulo State. In all representatives the leaves are dorsiventral and hypostomatic and present bicollateral vascular bundles in the midrib (except for one species). Some features such as type and position of the stomata and the aspect of the midrib surface vary even within a single genus. Other features like cuticle thickness, thricomes morphology, and occurrence or not of emergences, percentage of palisade parenchyma and position and shape of the main vascular bundle may help on the characterization of each genus when analyzed as a hole, within the tribes. These features are described for the 22 species and discussed in a systematic context.
\end{abstract}

Key words - cerrado, leaf anatomy, Melastomataceae

RESUMO - (Anatomia foliar de Melastomataceae do Cerrado do Estado de São Paulo). Foi estudada a estrutura foliar de 22 espécies de Melastomataceae (tribos Miconieae, Tibouchinieae e Microlicieae) encontradas no cerrado do estado de São Paulo. Em todos os representantes, as folhas são dorsiventrais e hipostomáticas e a nervura principal é formada por xilema e por floema nas duas faces (exceto por uma única espécie). Determinados caracteres presentes nesses órgãos, como tipo e posição dos estômatos e aspecto das superfícies adaxial e abaxial, na região da nervura principal, variam consideravelmente dentro de um mesmo gênero. Outros como espessura da cutícula nas duas superfícies, tipo e morfologia dos tricomas, presença ou não de emergências, porcentagem de parênquima paliçádico e posição e forma do sistema vascular principal, quando considerados em conjunto podem auxiliar na caracterização dos diferentes gêneros dentro das tribos. Esses aspectos são descritos para os 22 representantes estudados e discutidos dentro de um contexto sistemático.

Palavras-chave - anatomia foliar, cerrado, Melastomataceae

\section{Introdução}

Os cerrados correspondem a $25 \%$ do território nacional (Joly 1970, Hueck 1978, Ferri 1980, Ratter et al. 1997) e caracterizam-se pela presença de dois estratos na vegetação: um mais ou menos contínuo e aberto, formado por árvores baixas, de troncos e galhos retorcidos e outro descontínuo, constituído por gramíneas, subarbustos e poucas ervas (Rizzini 1979). Sua flora é bastante diversificada e abriga cerca de 6.062 espécies de fanerógamas, distribuídas em 1.093 gêneros e 151 famílias, e 267 espécies de pteridófitas, distribuídas em 51 gêneros e 19 famílias (Mendonça et al. 1998).

Grande parte dos estudos sobre a vegetação de cerrado, particularmente aqueles realizados no estado de São Paulo, são de cunho fitossociológico (Gibbs et al. 1983, Mantovani 1983 e 1987, Ferracini et al. 1983,

1. Parte da tese de doutorado de Claudia dos Reis. Universidade Estadual Paulista, Instituto de Biociências, Departamento de Botânica.

2. Universidade Estadual Paulista, Instituto de Biociências, Departamento de Botânica, Caixa Postal 199, 13506-900 Rio Claro, SP, Brasil.

3. Autor para correspondência: clau_dos_reis@hotmail.com
Toledo Filho 1984, Toledo Filho et al. 1984, Bicudo 1987 e 1995, Gianotti 1988, Cavassan 1990, Meira Neto 1991) e apesar do grande número de espécies típicas dessa vegetação, a morfo-anatomia foliar de seus representantes é pouco conhecida. Destacam-se os pioneiros estudos de Morretes $(1967,1969)$ e Morretes \& Ferri (1959), que descrevem a anatomia foliar de várias espécies, além de trabalhos mais restritos como os de Milanez (1951), Beiguelman (1962a, b, c, d), Panizza (1967), Handro $(1966,1967)$ e Paviani \& Ferreira (1974), sobre as folhas de alguns representantes.

A família Melastomataceae, que pertence à ordem Myrtales, agrupa cerca de 170 gêneros e aproximadamente 4.600 espécies, distribuídas nas regiões tropicais e subtropicais do mundo (Cronquist 1988, Barroso 1984). É subdividida em três subfamílias: Melastomoideae, com 11 tribos e Memecyloideae e Astronoideae, com apenas 1 tribo cada, e encontra-se bem representada nos cerrados do Estado de São Paulo, onde foram listadas 32 espécies (Heringer et al. 1977, Pagano et al. 1989, Mantovani 1983, 1987).

Como nos demais representantes da ordem Myrtales, em Melastomataceae as pontoações dos elementos de vaso do xilema secundário são guarnecidas (Metcalfe \& Chalk 1950, Keating 1984). 
As folhas, predominantemente dorsiventrais, são revestidas por células epidérmicas de tamanhos iguais, em ambas as faces, ou maiores na face adaxial. A cutícula pode ser espessa ou delgada e ornamentada ou simples e os estômatos podem ocorrer somente na face abaxial ou em ambas as faces (Keating 1984). Na região da nervura central, a face adaxial pode ser sulcada, plana ou ter forma de cunha enquanto que a face abaxial pode ser convexa ou arredondada. Os feixes vasculares podem aparecer imersos no mesofilo ou serem abruptamente diferenciados dele (Keating 1984); podem ser colaterais ou bicolaterais, sendo que os últimos apresentam ocasionalmente o floema mais desenvolvido no lado adaxial (Keating 1984). Esclereídes podem ou não estar presentes e cristais de oxalato de cálcio sempre aparecem dispersos aleatoriamente no mesofilo, ocorrendo em regiões superficiais ou próximos aos feixes vasculares (Keating 1984).

As folhas das Melastomataceae são, geralmente, pilosas, opostas ou opostas-cruzadas e pecioladas, com lâminas inteiras, lanceoladas, ovadas ou oblongas e com margens lisas ou serreadas. Os tricomas, de formas variadas e complexas, constituem um importante auxílio na identificação dos gêneros e espécies de Melastomataceae, sendo rara a ocorrência de tricomas simples (Metcalfe \& Chalk 1950). A epiderme, muitas vezes, é composta por células mucilaginosas de lume grande e é freqüente a presença de hipoderme (Metcalfe \& Chalk 1950).

Poucos são os estudos sobre a anatomia de representantes de Melastomataceae, destacando-se os trabalhos de Costa (1977), sobre o desenvolvimento caulinar e foliar de Miconia theaezans, os de Baumgratz \& Ferreira (1980, 1984), sobre venação e epiderme foliar de espécies de Miconia, o de Baas (1981), que descreve uma grande variedade de cristais e tipos de estômatos, nas folhas de 25 gêneros da família, e o de Wurdack (1986), um atlas sobre os inúmeros tipos de tricomas, encontrados nos representantes neotropicais. Num estudo sobre a morfologia dos estômatos, de diversas Myrtales (incluindo algumas Melastomataceae), Ramassamy \& Kannabiran (1996) reconhecem cinco grupos, com base na inserção, orientação e posição das células subsidiárias, mostrando que esse caráter pode ser usado na delimitação das espécies.

O presente estudo descreve a anatomia foliar de 22 espécies de Melastomataceae, que ocorrem no Cerrado do Estado de São Paulo, com os objetivos de contribuir para o conhecimento anatômico da família e apontar caracteres úteis na delimitação de seus táxons.

\section{Material e métodos}

O estudo foi realizado com folhas adultas de 22 espécies de Melastomataceae, de hábito arbóreo-arbustivo, exceto por Microlia polystemma Naudin, que é herbácea. O material foi coletado em ambiente de cerrado, nos municípios de Itirapina, Analândia e Botucatu, e em cerradão, em Corumbataí. Nessas localidades o clima é do tipo Cwa, de Koeppen, mesotérmico com inverno seco.

O material, coletado geralmente em estado vegetativo, foi identificado pelo Prof. Dr. Renato Goldenberg (Universidade Federal do Paraná), e se encontra incluído no Herbário Rioclarense (HRCB) para referência. Foram estudadas, também, folhas herborizadas de representantes que estão depositados neste mesmo herbário (HRCB), marcados abaixo com asterisco.

Tribo Miconieae: *Leandra aurea (Cham.) Cogn. (HRCB6275); *L. lacunosa Cogn. (HRCB2789). Miconia: Seção Miconia-Seriatiflora: M. albicans (Sw.) Triana (HRCB39006); M. fallax DC. (HRCB39014); M. stenostachya Schrank \& Mart. ex DC. (HRCB39013); Seção MiconiaPaniculares: ${ }^{*}$ M. chamissois Naudin (HRCB28940); $M$. rubiginosa (Bonpl.) DC. (HRCB39009); M. chartacea Triana (HRCB39007); M. ligustroides (DC.) Naudin (HRCB5471); *M. minutiflora DC. (HRCB28581); M. pepericarpa Mart. ex DC. (HRCB39016); Seção Cremanium: *M. hyemalis A. St.-Hil. \& Naudin ex Naudin (HRCB20176); Seção Jucunda: *M. langsdorffii Cogn. (HRCB5471); Seção Chaenanthera: *M. sellowiana Naudin (HRCB5956); Miconia sp. (HRCB39010).

Tribo Microlicieae: Microlicia polystemma Naudin (HRCB39008).

Tribo Tibouchinieae: *Acisanthera alsinaefolia (Mart. \& Schr. ex DC.) Triana (HRCB29695); *Microlepsis oleaefolia (DC.) Triana (HRCB28031); *Tibouchina gracilis (Bonpl.) Cogn (HRCB39015); *Tibouchina stenocarpa (DC.) Cogn (HRCB30346); Tibouchina sp. 1 (HRCB39011); Tibouchina sp. 2 (HRCB39012).

Para a análise anatômica, utilizaram-se folhas situadas entre o $3^{\circ}$ e o $8^{\circ}$ nós. O material coletado foi levado ao laboratório, fixado em FAA 50 e estocado em etanol 50\% glicerinado. As folhas de herbário foram re-hidratadas, em água destilada e glicerina, e aquecidas em forno de microondas por cerca de 2 minutos, dependendo do material. As seções histológicas foram realizadas à mão-livre, na região mediana da lâmina e, sempre que necessário, os limbos foram divididos em nervura principal e bordo. As secções, transversais e paradérmicas, foram clareadas em água sanitária a $20 \%$, coradas com azul de astra e safranina (safrablau) (Bukatsch 1972 apud Kraus \& Arduin 1997) e montados em lâminas semi-permanentes, com gelatina glicerinada (Johansen 1940).

Para determinar a porcentagem de parênquima paliçádico foi feito, para todas os representantes e com auxílio de estereomicroscópio, um diagrama delimitando as diferentes 
regiões do mesofilo. Nessas ilustrações, elaboradas todas na mesma escala, foi medida a porcentagem ocupada por tal tecido.

Para os testes microquímicos, cortes transversais do limbo foram submetidos aos seguintes reagentes: solução aquosa de cloreto férrico a $10 \%$, adicionada de pequena porção de carbonato de cálcio (Johansen 1940) para a localização de compostos fenólicos, e floroglucina ácida (Sass 1951) para evidenciar paredes lignificadas.

Os resultados foram representados através de fotomicrografias obtidas num fotomicroscópio Olympus BX40.

\section{Resultados}

Em vista frontal, as células epidérmicas possuem contorno poligonal (figuras 1-3). Na face adaxial as paredes anticlinais são retas, em Miconia (figura 1), e levemente sinuosas, em Leandra (figura 2), gêneros incluídos na Tribo Miconieae. Na tribo Tibouchinieae, essas paredes são sempre retas, como observado em Acisanthera (figura 3). Na face abaxial as paredes anticlinais são sinuosas nos representantes das duas Tribos (figuras 4, 5). Em Microlicia polystemma (figura 6) (Tribo Microlicieae) as paredes anticlinais são levemente sinuosas nas duas faces foliares, observando-se também uma ornamentação na cutícula em forma de estrias paralelas, longas e contínuas, recobrindo várias células, inclusive as dos complexos estomáticos. Dentro da Tribo Miconieae são encontrados estômatos anomocíticos, como ilustrado na figura 4, em Leandra e Miconia; anisocíticos, como ilustrado na figura 6, em Leandra e Miconia; e diacíticos, em Miconia; apenas Miconia rubiginosa (figura 5) e Miconia fallax, apresentam estômatos do tipo polocítico (tabela 1). Os representantes da Tribo Tibouchinieae possuem estômatos anomocíticos, como em Acisanthera alsinaefolia (figura 4). Em Microlicia polystemma (figura 6) os estômatos são anisocíticos e/ou diacíticos (tabela 2). Com exceção de Microlicia polystemma (figura 7), com folhas anfistomáticas, todas as espécies estudadas possuem estômatos restritos à superfície abaxial (figuras 8-12).

A epiderme é geralmente uniestraficada. Nas folhas de Tibouchina (figuras 8, 9) e Microlepsis (Tribo Tibouchinieae) e de Miconia (figuras 10, 11) e Leandra (Tribo Miconieae), as células da face adaxial são maiores que as da face abaxial e variam de quadradas a retangulares, em corte transversal. Em Miconia chartaceae (figura 10) observa-se epiderme ocasionalmente bi-estratificadas, na face adaxial, e em M. sellowiana (figura 11) células papilosas, na face abaxial. Nas folhas de Acisanthera (figura 12) (Tribo
Tibouchinieae), as células da face adaxial são bem desenvolvidas anticlinalmente e divididas periclinalmente, em alguns pontos. Em Microlicia polystemma (figura 7) (Tribo Microlicieae) as duas faces da epiderme são formadas por células de tamanhos semelhantes.

Nas folhas de Miconia (figuras 10, 11) e Leandra (Tribo Miconieae) a cutícula é, em geral, mais espessa na face adaxial e pode se apresentar ornamentada (tabela 1). Em Tibouchina (figuras 8, 9), Acisanthera (figura 12), Microlepsis (Tribo Tibouchinieae) e em Microlicia (figura 7) (Tribo Microlicieae), as duas faces foliares são revestidas por cutícula delgada.

Tricomas tectores são freqüentes nas lâminas de Miconia (figuras 10, 28, 29), Leandra (figura 14) (Tribo Miconieae) e Microlepsis (figura 15) (Tribo Tibouchinieae), podendo ser dendríticos ou ramificados. Em Leandra (figura 14) e Microlepsis (figura 15) eles são ramificados e em Miconia (figuras 10, 28, 29) dendríticos e/ou ramificados (tabelas 1, 2), sendo que neste último gênero eles ocorrem apenas na superfície abaxial. Folhas glabras são encontradas somente em Miconia chamissois. Acisanthera (figura 16) e Tibouchina (figura 17) (Tribo Tibouchinieae) possuem tricomas glandulares, que são plurisseriados em Acisanthera (figura 16) e unisseriados em Tibouchina (figura 17) (tabela 2). Em Microlicia polystemma (figura 7, 13) (Tribo Microlicieae) são encontrados tricomas tectores bisseriados (figura 13) e glandulares unisseriados (figura 7; tabela 2).

Nas folhas de Leandra (figura 18) (Tribo Miconieae), Tibouchina (figura 9, 19) e Microlepsis (figura 20) (Tribo Tibouchinieae) é comum a presença de emergências formadas por tecido epidérmico e por esclereídes entremeadas às células parenquimáticas, na porção interna, como ilustrado na figura 21 (tabelas 1, 2). Em Microlepsis (figura 20) as emergências restringemse à face adaxial sendo revestidas por epiderme portadora de tricomas tectores. Em Leandra e Tibouchina elas aparecem nas duas faces foliares e são recobertas por epiderme papilosa em Tibouchina (figura 19) e por células comuns em Leandra (figura 18). Tricomas glandulares unisseriados, geralmente, encontram-se associados às emergências de Tibouchina (figura 17).

Os estômatos são levemente projetados em relação às demais células epidérmicas, em Microlicia (figura 7) (Tribo Microlicieae), na maioria das Miconia (figuras 10, 11) (Tribo Miconieae), em Acisanthera (figura 12) (Tribo Tibouchinieae) e em Leandra. Em Tibouchina (figura 9) e Microlepsis (Tribo Tibouchinieae), eles ocupam o mesmo nível das demais células epidérmicas. 
Adjacente à superfície adaxial observa-se, nas folhas de algumas Tibouchina (figura 9) (Tribo Tibouchinieae) e de Microlepsis, uma hipoderme formada por 2-3 camadas de células maiores que as da epiderme. Esse tecido é, ocasionalmente, interrompido por esclereídes e idioblastos contendo drusas que, junto com a epiderme, formam as emergências características desses gêneros (figuras 9, 21).
O mesofilo, em Microlicia (figura 7) (Tribo Microlicieae) é isobilateral, formado por uma camada de parênquima paliçádico, nas faces adaxial e abaxial e por 3-4 camadas de parênquima lacunoso no centro. Nas demais espécies estudadas, o mesofilo é dorsiventral, como representados pelas figuras 8-11. Em Miconia sellowiana (figura 11), o parênquima lacunoso voltado para a face abaxial apresenta células desenvolvidas,
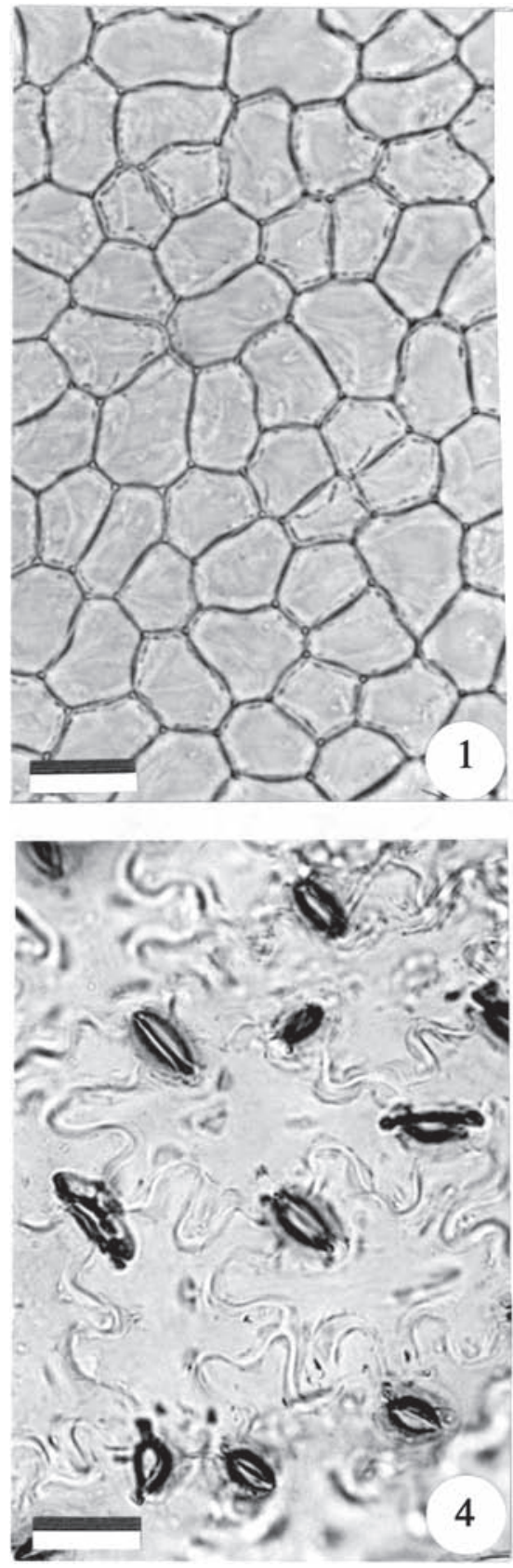
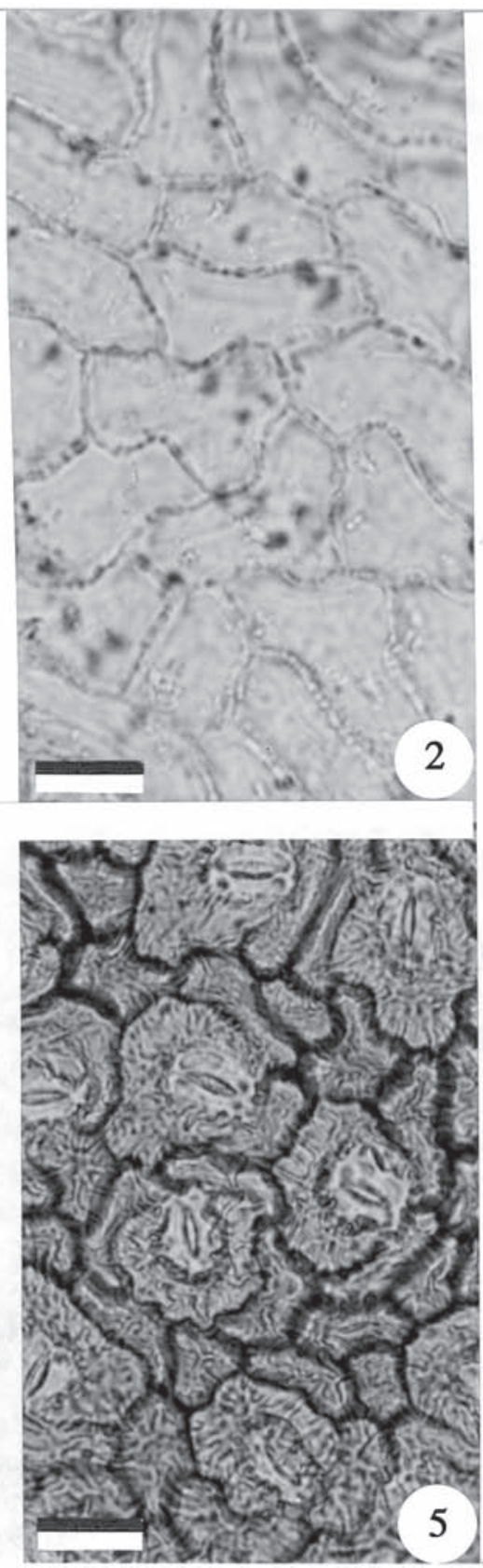
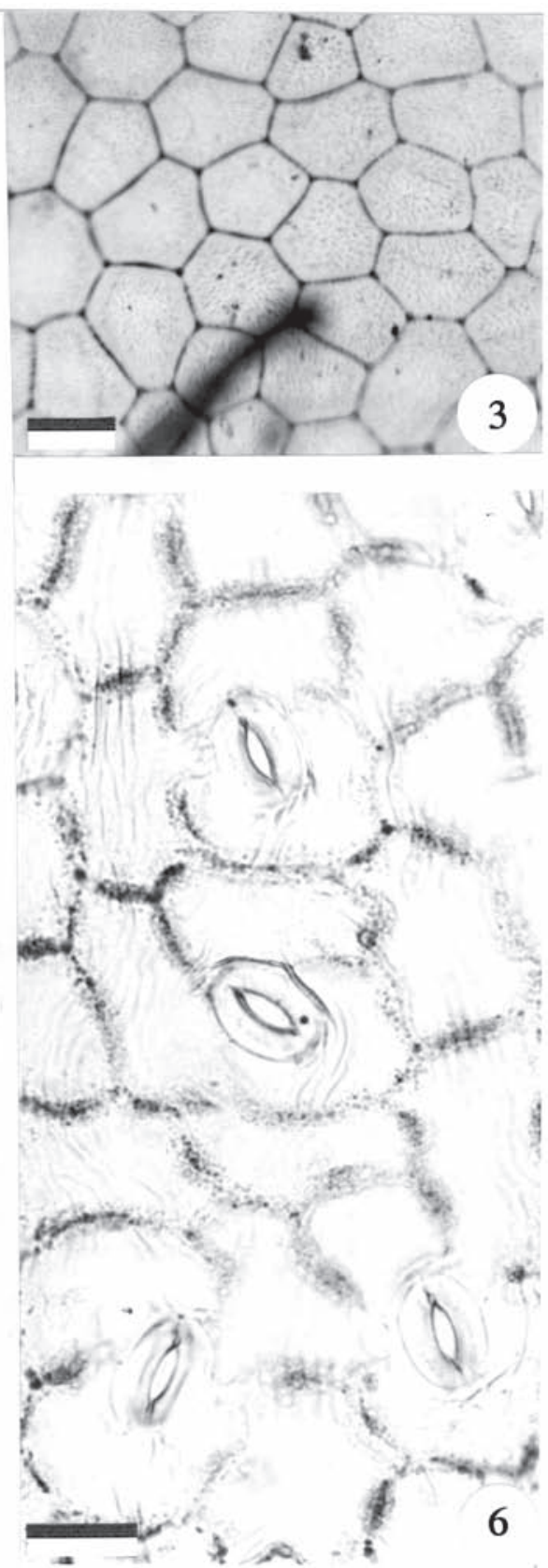

Figuras 1-6. Epiderme em vista frontal. 1-3. Face adaxial. 4-6. Face abaxial. 1. Miconia stenostachya. 2. Leandra aurea. 3-4. Acisanthera alsinaefolia. 5. Miconia rubiginosa. 6. Microlicia polystemma. Barras $=20 \mu \mathrm{m}(1-2,4-6)$; $70 \mu \mathrm{m}(3)$.

Figures 1-6. Epidermis in frontal view. 1-3. Adaxial surface. 4-6. Abaxial surface. 1. Miconia stenostachya. 2. Leandra aurea. 3-4. Acisanthera alsinaefolia. 5. Miconia rubiginosa. 6. Microlicia polystemma. Bars $=20 \mu \mathrm{m}(1-2,4-6)$; 70 $\mu \mathrm{m}(3)$. 


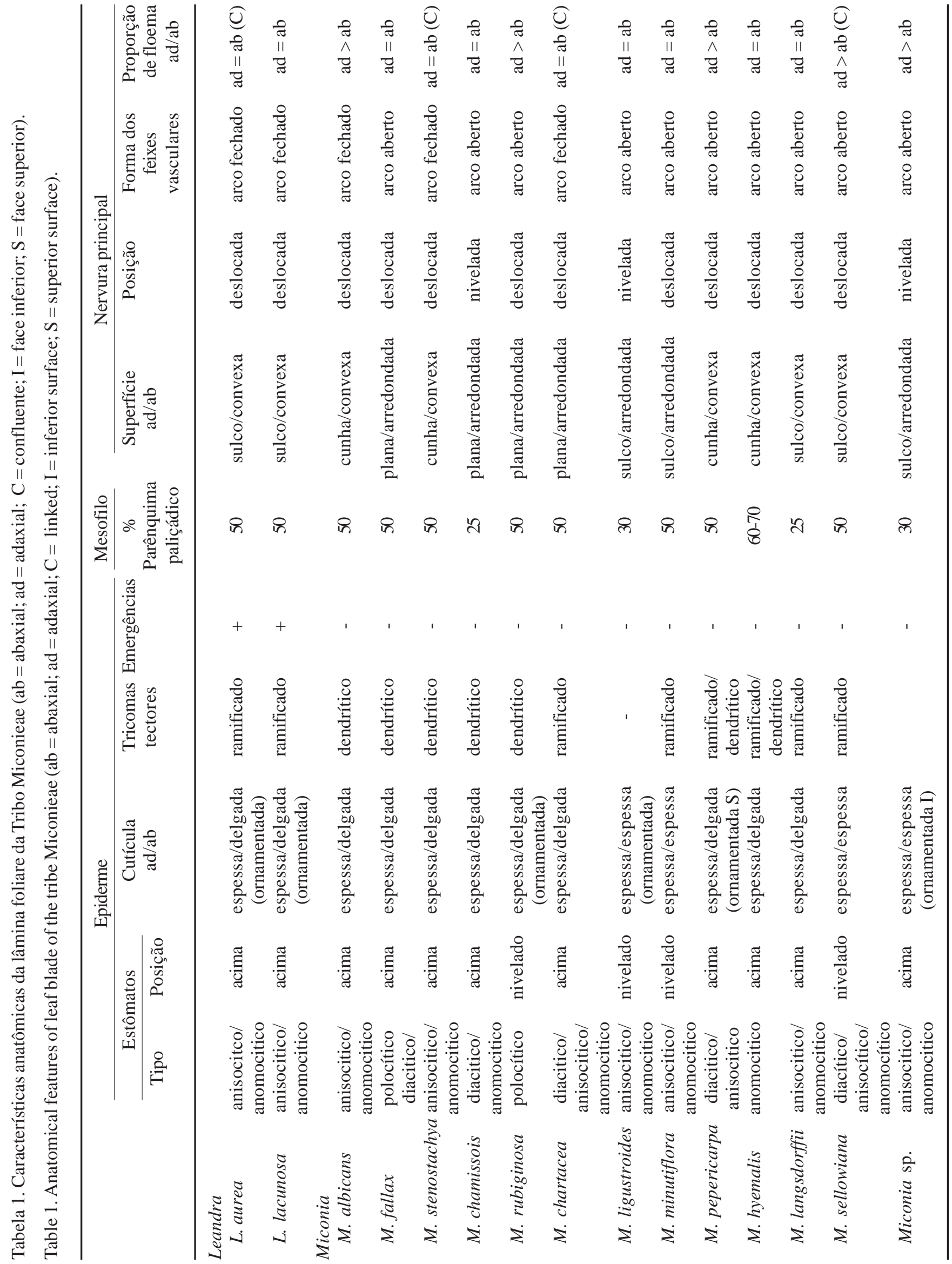




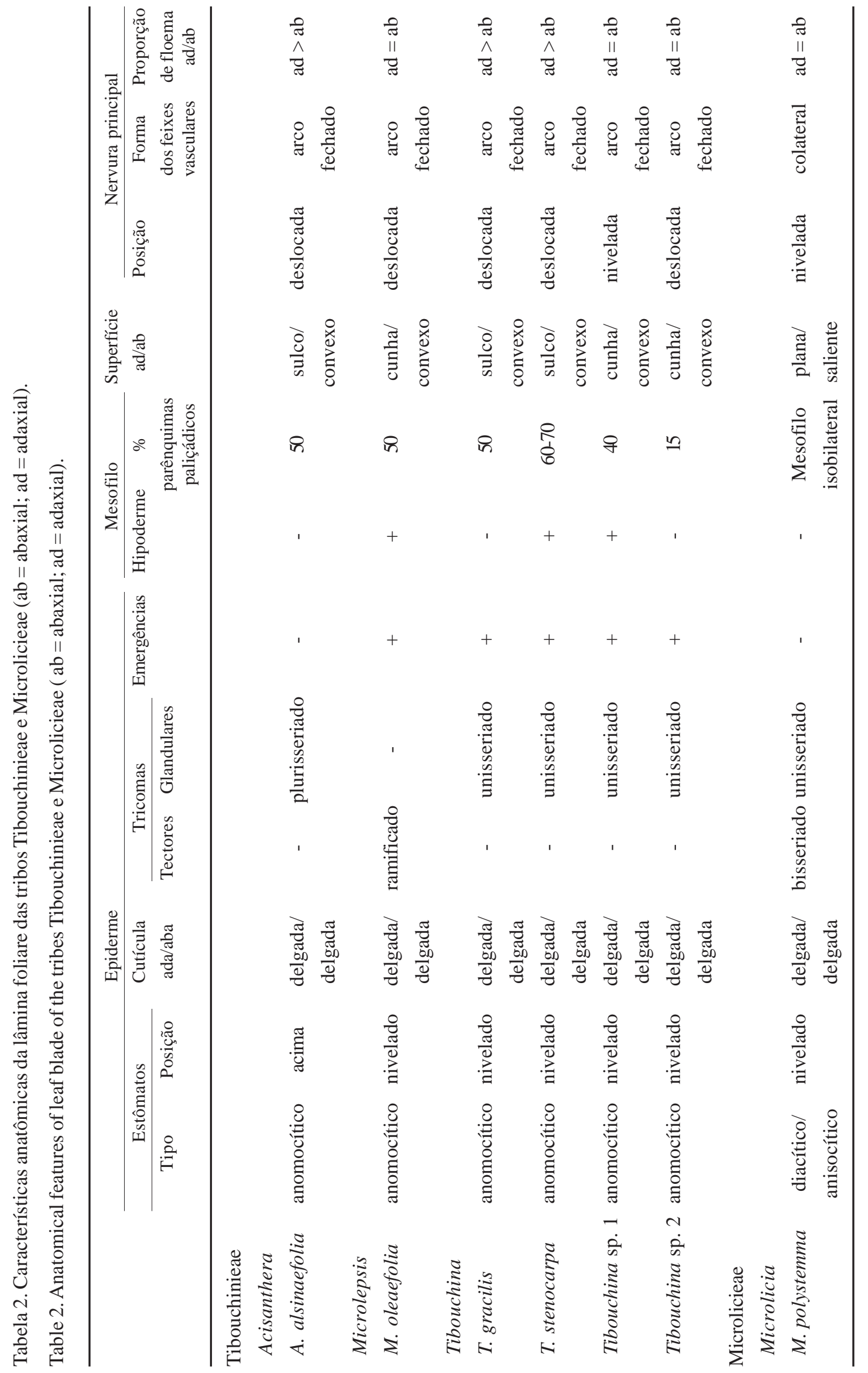



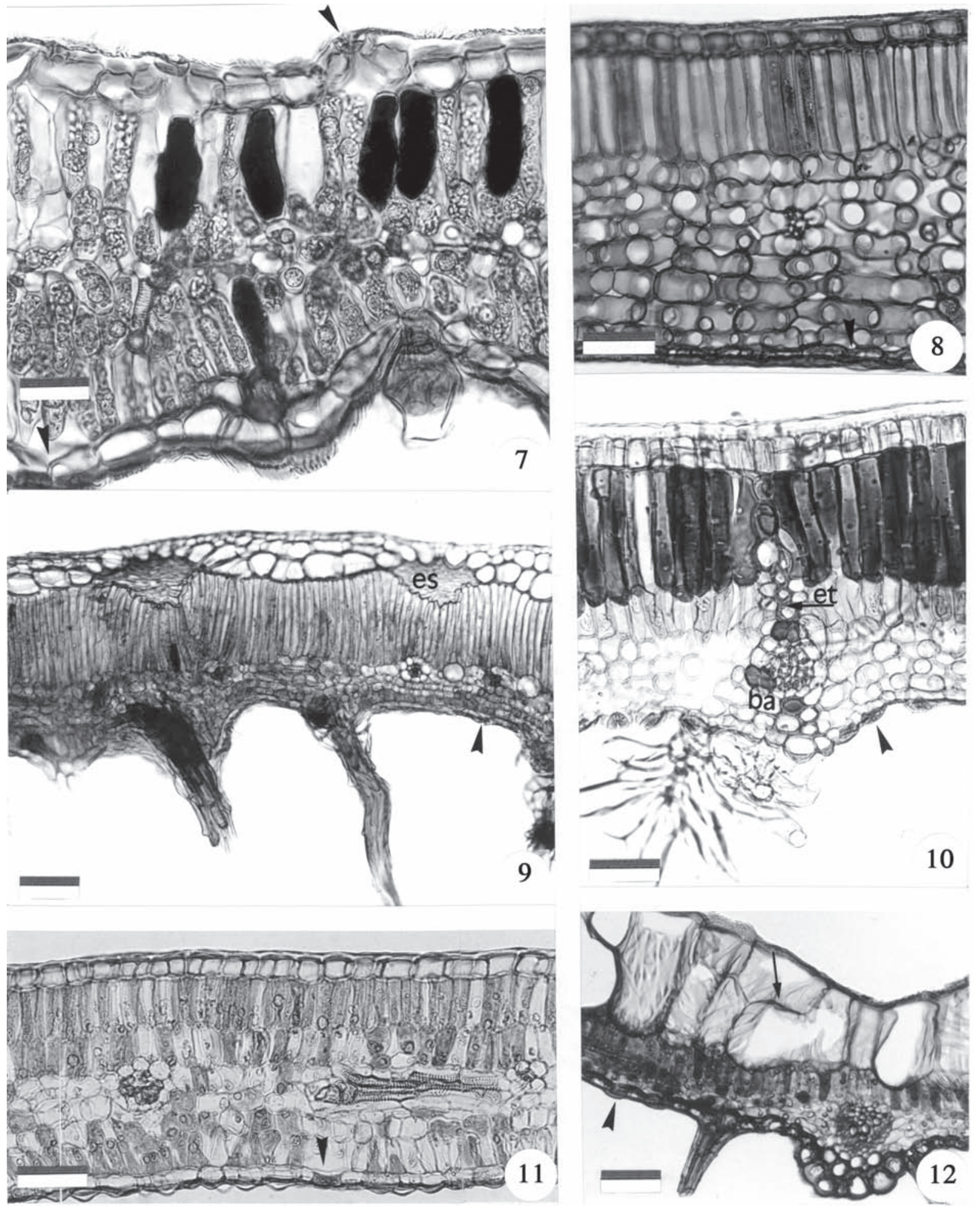

Figuras 7-12. Secções transversais da lâmina foliar. 7. Microlicia polystemma. 8. Tibouchina sp.1. 9. Tibouchina stenocarpa. 10. Miconia chartacea. 11. Miconia sellowiana. 12. Acisanthera alsinaefolia . (ponta de seta = estômato; seta = divisão periclinal da célula epidérmica; ba = bainha; et = extensão de bainha; es = esclereides). Barras = $40 \mu \mathrm{m}(7-8,10-11) ; 70 \mu \mathrm{m}(9,12)$.

Figures 7-12. Leaf in cross section. 7. Microlicia polystemma. 8. Tibouchina sp.1. 9. Tibouchina stenocarpa. 10. Miconia chartacea. 11. Miconia sellowiana. 12. Acisanthera alsinaefolia . arrowhead $=$ stomata; arrow $=$ periclinal division on the epidermal cell; $\mathrm{ba}=$ vascular bundle sheaths; et $=$ extension of the vascular bundle sheaths; es $=$ sclereides $)$. Bars $=40 \mu \mathrm{m}(7-8$, $10-11) ; 70 \mu \mathrm{m}(9,12)$. 

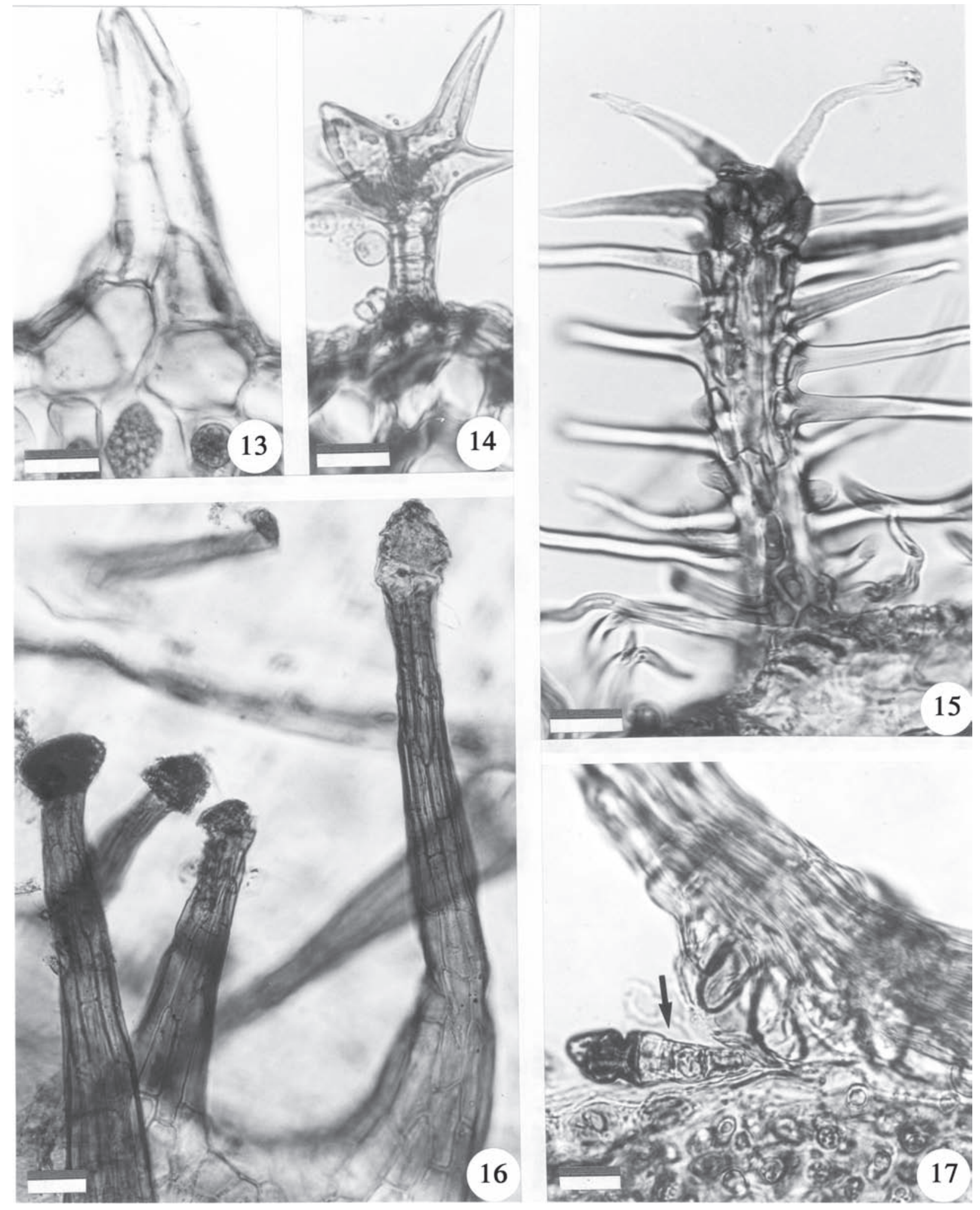

Figuras 13-17. Tricomas. 13. Microlicia polystemma - tector bisseriado. 14. Leandra lacunosa - tector ramificado. 15. Microlepsis oleaefolia - tector ramificado. 16. Acisanthera alsinaefolia - glandular plurisseriado. 17. Tibouchina stenocarpa - glandular unisseriado (seta). Barras $=20 \mu \mathrm{m}(13-15,17) ; 30 \mu \mathrm{m}$ (16).

Figures 13-17. Trichomes. 13. Microlicia polystemma - tector biseriate. 14. Leandra lacunosa - tector branched. 15. Microlepsis oleaefolia - tector branched. 16. Acisanthera alsinaefolia - glandular pluriseriate. 17. Tibouchina stenocarpa - glandular uniseriate (arrow). Bars $=20 \mu \mathrm{m}(13-15,17) ; 30 \mu \mathrm{m}(16)$. 
anticlinalmente, conferindo ao mesofilo um aspecto semelhante ao isobilateral. Na maioria das Miconia (figuras 10, 11), em Leandra (Tribo Miconieae), Acisanthera (figura 12) e Microlepsis (Tribo Tibouchinieae), o parênquima paliçádico ocupa aproximadamente $50 \%$ da espessura do mesofilo. Em Tibouchina (figura 8, 9) (Tribo Tibouchinieae) a espessura da camada de parênquima paliçádico varia de $40 \%$ a $70 \%$ da espessura do mesofilo. O parênquima lacunoso, no geral, apresenta arranjo compacto com poucos espaços intercelulares, conforme ilustrados nas figuras 7 a 12.

Em todos os representantes estudados, os feixes vasculares secundários são colaterais e apresentam-se envolvidos por bainha conspícua de células parenquimáticas e possuem extensão de bainha parenquimática, conforme observado em Miconia chartaceae (figura 10).

Na região da nervura principal, a maioria das folhas estudadas apresenta superfície adaxial sulcada ou em cunha e superfície abaxial convexa (figuras 22-24; tabelas 1,2); entretanto, em M. chartaceae (figura 26), Miconia sp. (figura 27), M. chamissois, M. falax, e M. rubiginosa as folhas são planas adaxialmente e convexas abaxialmente. Somente em três espécies de Miconia (Tribo Miconieae), numa espécie de Tibouchina (Tribo Tibouchinieae) e em Microlicia polystemma (Tribo Microlicieae) a nervura principal é nivelada com o mesofilo (figuras 25, 27; tabelas 1,2). O sistema vascular é formado por xilema e por floema nas posições adaxial e abaxial (figuras 22-24, 26-27), exceto por Microlicia polystema (figura 25) (Tribo Microlicieae) onde as unidades são colaterais. O floema adaxial é mais desenvolvido que o abaxial em Miconia sp. (figura 27), Miconia sellowiana, Miconia albicans, M. rubiginosa, M. pepericarpa (Tribo Miconieae) e em Tibouchina sp. 2 (figura 22), T. gracilis e T. stenocarpa (Tribo Tibouchinieae). Nas folhas das demais espécies estudadas, os floemas adaxial e abaxial aparecem na mesma proporção. Em determinados representantes, como Leandra lacunosa (figura 24), L. aurea, Miconia sellowiana, M. chamissois, M. stenostachya, M. pepericarpa (Tribo Miconieae) e Tibouchina stenocarpa (Tribo Tibouchinieae) o floema adaxial é confluente com o abaxial no bordo do feixe.

O sistema vascular apresenta a forma de arco aberto em Tibouchina (figura 22) (Tribo Tibouchinieae) e na maioria das Miconia (figura 27) (Tribo Miconieae) (tabelas 1,2). Entretanto, ele é um arco quase fechado em Leandra (figura 24), Miconia albicans e
M. stenostachya (Tribo Miconieae) e em Microlepsis (figura 23), Acisanthera e Tibouchina stenocarpa (Tribo Tibouchinieae). Em Miconia chartacea (figura 26) o sistema vascular é constituído por uma unidade bicolateral grande, em forma de arco, por duas unidades bicolaterais invertidas e por feixes anficrivais pequenos em posição adaxial. Na folha de Microlepsis (figura 23), observa-se fibras adjacentes ao floema, nas duas faces.

Ainda na região da nervura principal, observam-se quatro a cinco camadas de colênquima angular adjacentes à superfície abaxial (figura 22) ou à superfície abaxial e adaxial, onde esse tecido interrompe o parênquima paliçádico (figuras 26, 27).

Nas folhas de determinados representantes, como Miconia albicans (figura 28), M. hyemalis (figura 29), M. chartaceae, M. langsdorffii, M. falax, M. minutiflora, M. ligustroides (Tribo Miconieae), Acisanthera e Microlepsis (Tribo Tibouchinieae), os feixes vasculares laterais são deslocados abaxialmente. Esses feixes são colaterais em todas as espécies estudadas.

Células esclerificadas distribuem-se aleatoriamente na região da nervura principal das folhas de Leandra (figura 24) e Miconia (figura 27) (Tribo Miconieae) e de Tibouchina e Microlepsis (Tribo Tibouchinieae) e idioblastos contendo drusas ou substâncias fenólicas (figuras 23-24, 26-27) também são freqüentes nas folhas dos representantes estudados.

\section{Discussão}

Em Melastomataceae, as lâminas foliares são predominantemente dorsiventrais e hipostomáticas, conforme observado para Miconia por Costa (1977), Baumgratz \& Ferreira (1980), Souza \& Marquete (2000) e para Tibouchina pulchra por Vecchi (1999). Somente em Microlicia polystemma verificam-se folhas anfistomáticas. Os estômatos são, em geral, anomocíticos ou anisocíticos, embora os tipos diacítico e polocítico, também estejam presentes (Metcalfe \& Chalk 1950). Num abrangente estudo, Baas (1981), verificou que na subfamília Melastomoideae os estômatos são, em geral, polocíticos e diacíticos enquanto que em Memecyloideae e Crypteronioideae predominam os tipos paracíticos e anomocíticos. Nas espécies aqui estudadas, que pertencem à subfamília Melastomoideae, estômatos diacíticos e anisocíticos ocorrem em Microlicia (tribo Microlicieae) e em algumas Miconia (tribo Miconieae); estômatos anisocíticos e anomocíticos aparecem em Leandra e Miconia (tribo Miconieae), enquanto que 
os representantes da tribo Tibouchinieae apresentam somente estômatos anomocíticos. Em algumas espécies de Miconia, eles estão rodeados quase que inteiramente por uma única célula (polocítico), característica já descrita para outros representantes da família (Metcalfe \& Chalk 1950), incluindo espécies de Lavoisiera (Sousa 1997). Segundo Costa (1977), em Miconia theaezans, os estômatos são diacíticos, anomocíticos e de transição e nas espécies deste mesmo gênero, estudadas por
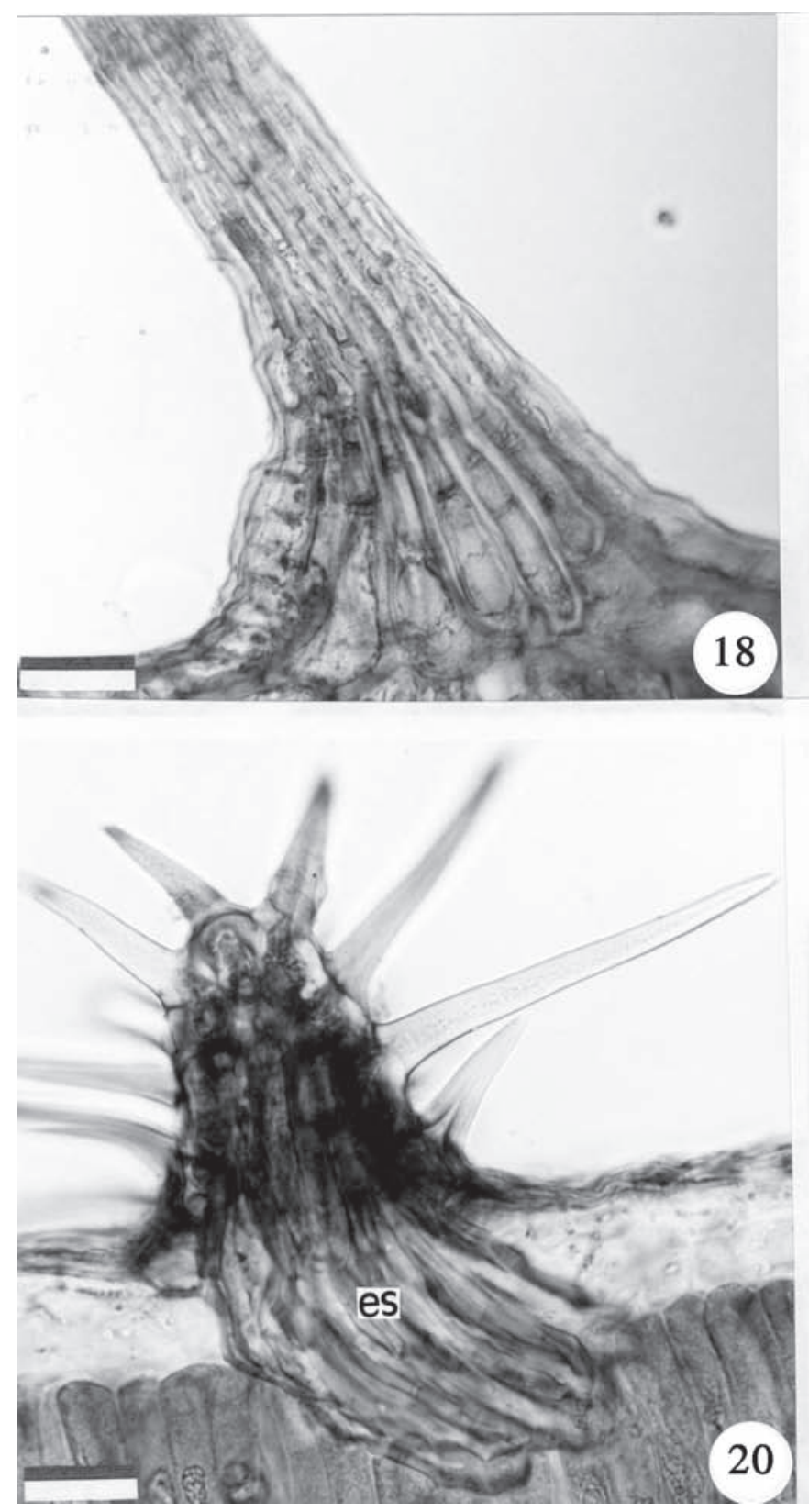

Baumgratz \& Ferreira (1980), os estômatos são diacíticos, anisocíticos e anomocíticos, exceto em M. albicans que não possui estômatos anomocíticos e em $M$. calvescens onde não ocorrem estômatos diacíticos. Em Tibouchina pulchra (Vecchi 1999), os estômatos são anomocíticos, como aqui observado para os demais representantes da mesma tribo.

Embora estômatos nivelados caracterizem as folhas de Melastomataceae e da maioria dos representantes
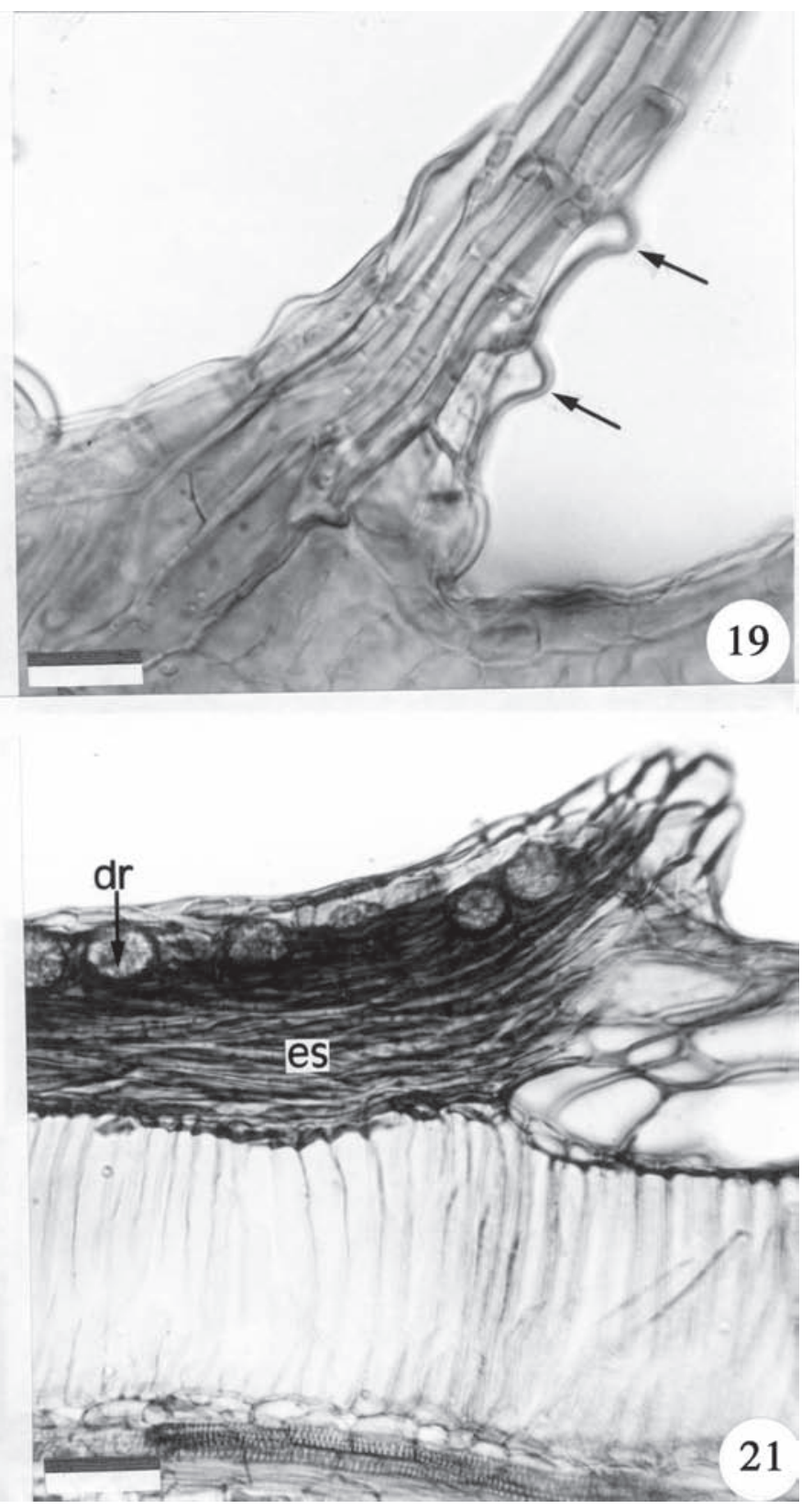

Figuras 18-21. Emergências. 18. Leandra lacumosa. 19. Tibouchina sp.2. 20. Microlepsis oleaefolia. 21. Tibouchina sp.2. (seta $=$ papilla; es $=$ esclereídes, $\mathrm{dr}=$ drusa $).$ Barras $=20 \mu \mathrm{m}(18-21)$.

Figures 18-21. Epidermis emergences. 18. Leandra lacumosa. 19. Tibouchina sp.2. 20. Microlepsis oleaefolia. 21. Tibouchina sp.2. $($ arrow $=$ papillae; $\mathrm{es}=$ sclereides; $\mathrm{dr}=$ druse $)$. Bars $=20 \mu \mathrm{m}(18-21)$. 
de Myrtales (Keating 1984), em algumas espécies de Miconia e Leandra (Tribo Miconieae) e em Microlepsis oleaefolia (Tribo Tibouchinieae), eles ocupam posição ligeiramente superior, conforme descrito para Miconia tristis e M. doriana por Souza \& Marquete (2000).
Em todas as folhas estudadas, a epiderme é uniestratificada, confirmando os resultados obtidos para Miconia (Costa 1977, Souza \& Marquete 2000) e para Tibouchina pulchra (Vecchi 1999). Em geral, a cutícula é mais espessa na face adaxial, embora algumas Miconia possuam folhas totalmente revestidas por
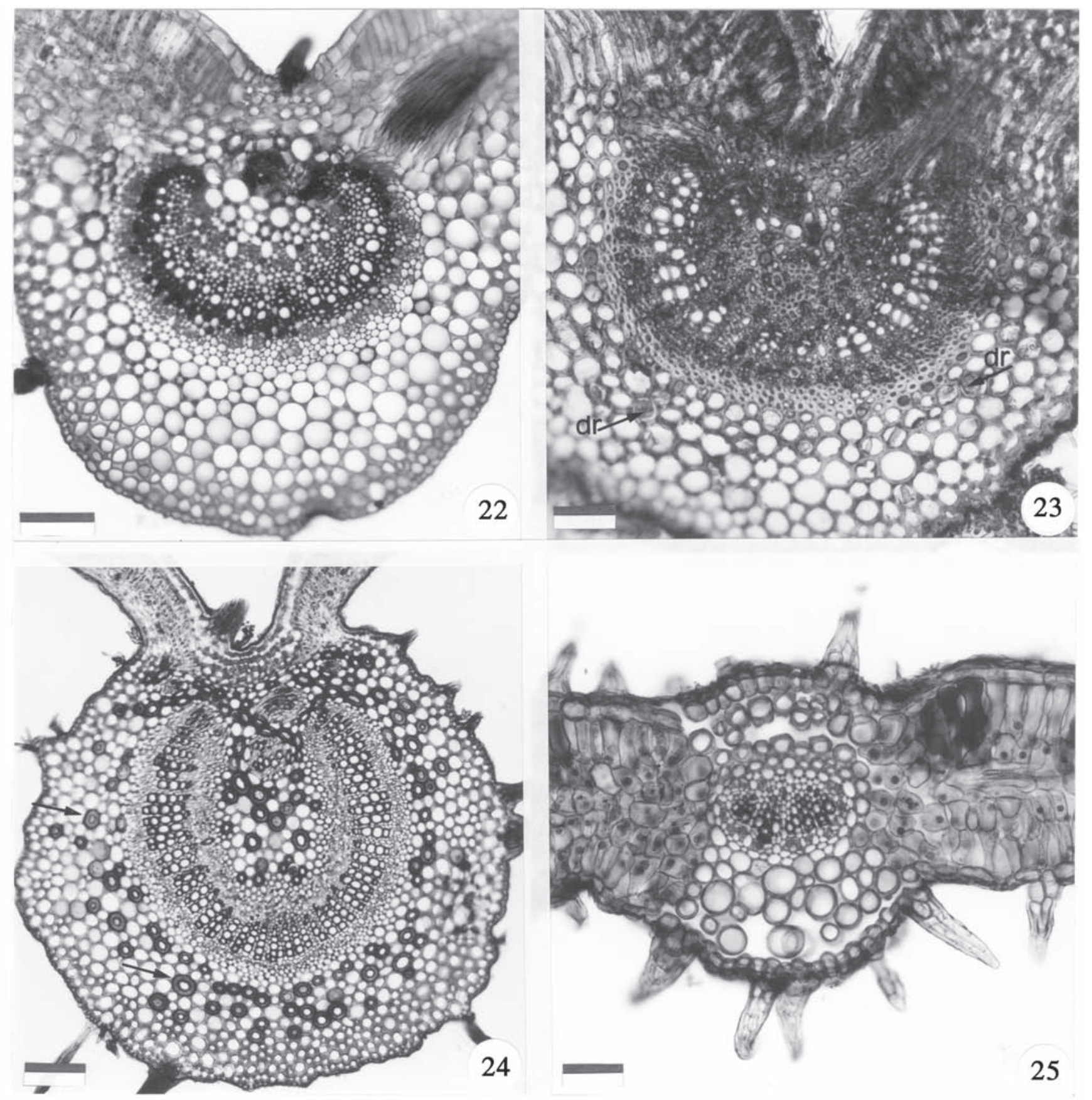

Figuras 22-25. Secções transversais da nervura principal. 22. Tibouchina sp.2. 23. Microlepsis oleaefolia. 24. Leandra lacunosa. 25. Microlicia polystemma. (seta = célula esclerificada; $\mathrm{dr}=$ drusa). Barras $=70 \mu \mathrm{m}(22,25) ; 140 \mu \mathrm{m}(24) ; 200 \mu \mathrm{m}(23)$.

Figures 22-25. Cross sections of the midrib. 22. Tibouchina sp.2. 23. Microlepsis oleaefolia. 24. Leandra lacunosa. 25. Microlicia polystemma. (arrow $=$ sclerenchymatous cell; $\mathrm{dr}=$ druse). Bars $=70 \mu \mathrm{m}(22,25) ; 140 \mu \mathrm{m}(24) ; 200 \mu \mathrm{m}(23)$. 
cutícula espessa, como observado por Costa (1977) para Miconia theazans; já as folhas das espécies de Miconia, estudadas por Souza \& Marquete (2000), são revestidas por cutícula delgada.

Células epidérmicas da face adaxial maiores que as da face abaxial predominam nas folhas das tribos
Miconieae e Tibouchinieae; em Microlicieae elas possuem tamanhos semelhantes em ambas as faces. Dentro de Myrtales, células epidérmicas maiores na face adaxial ocorrem em representantes de Lythraceae, Rynchocalycaceae, Trapaceae, Oliniaceae, Combretaceae, Penaeaceae, Psiloxylaceae, Myrtaceae,
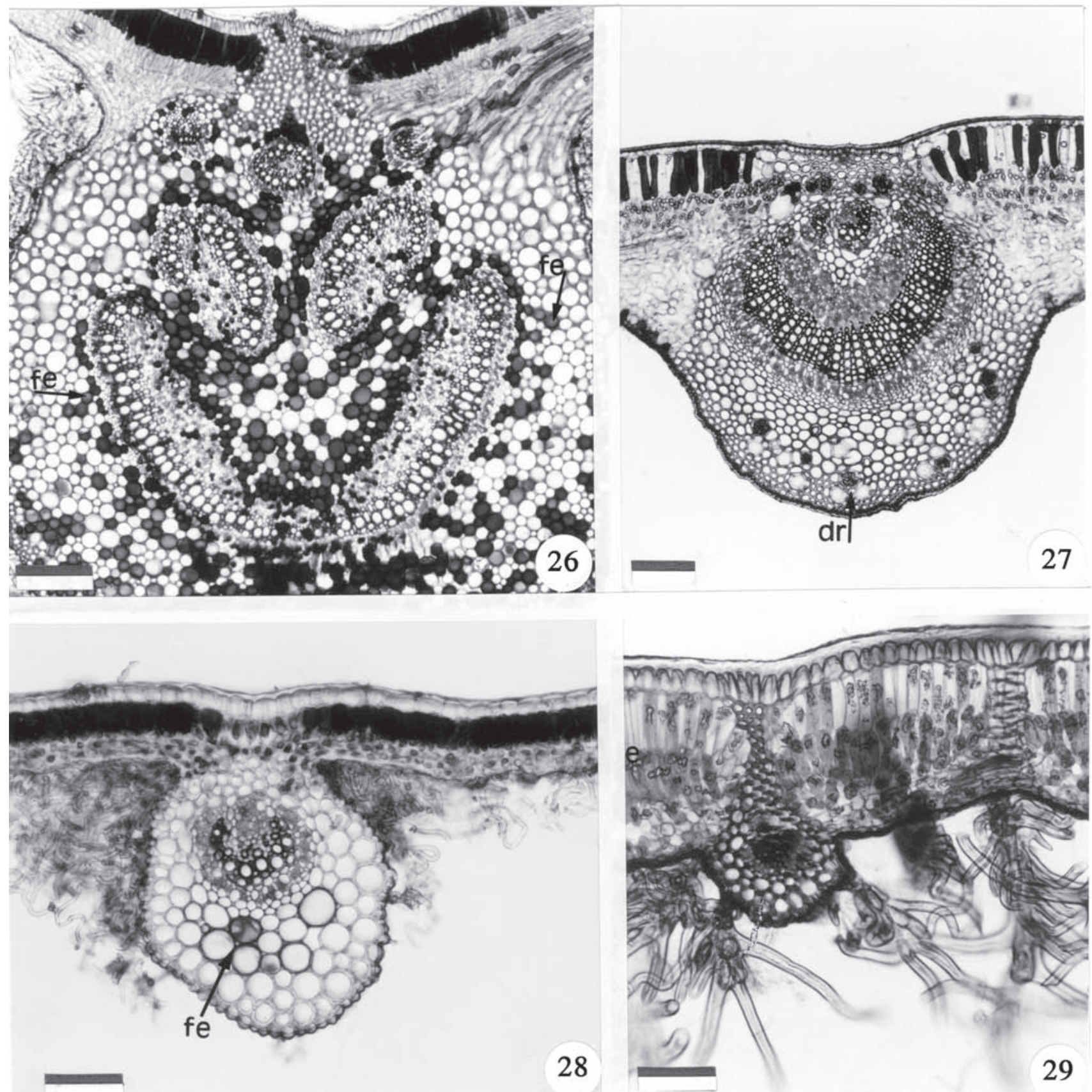

Figuras 26-27. Secções transversais da nervura principal de Miconia. 26. M. chartacea. 27. Miconia sp. 28-29. Secções transversais dos feixes vasculares laterais de Miconia. 28. M. albicans. 29. M. hyemalis. $(\mathrm{dr}=\mathrm{drusa}$; $\mathrm{fe}=$ substâncias fenólicas). Barras $=40 \mu \mathrm{m}(26) ; 140 \mu \mathrm{m}(27) ; 200 \mu \mathrm{m}(28-29)$.

Figures 26-27. Cross sections of the midrib of Miconia. 26. M. chartacea. 27. Miconia sp. 28-29. Cross sections of the lateral vascular bundle of Miconia. 28. M. albicans. 29. M. hyemalis. $(\mathrm{dr}=\mathrm{druse} ; \mathrm{fe}=$ phenolics substances $)$. Bars $=40 \mu \mathrm{m}(26)$; $140 \mu \mathrm{m}(27) ; 200 \mu \mathrm{m}(28-29)$. 
Onagraceae (Keating 1984) e Vochysiaceae (Sajo \& Rudall 2002). Células epidérmicas de mesmo tamanho caracterizam as folhas de algumas Lythraceae, Combretaceae, Alzateaceae, Penaeaceae, Myrtaceae, Onagraceae (Keating 1984) e Vochysiaceae (Sajo \& Rudall 2002).

Como observado para outras Myrtales (Keating 1984, Sajo \& Rudall 2002), as folhas de determinadas Tibouchinieae e de Microlepsis oleaefolia (Tribo Tibouchinieae) apresentam uma hipoderme adaxial. Embora em outros representantes da ordem esse tecido seja desenvolvido, nas espécies aqui estudadas ele não apresenta grande espessura.

Em algumas Miconia (tribo Miconieae) e Tibouchina (tribo Tibouchinieae), o tecido paliçádico apresenta-se desenvolvido ocupando $25 \%$ a $70 \%$ da espessura da lâmina, conforme descrito para Miconia theaezans (Costa 1977). Segundo Keating (1984), dentro de Myrtales, Melastomataceae é a família que apresenta a maior variação na proporção entre parênquima paliçádico e parênquima lacunoso.

Como em outros representantes da família (Costa 1977, Baumgratz \& Ferreira 1984, Keating 1984, Vecchi 1999, Souza \& Marquete 2000), os feixes vasculares da nervura principal são formados por xilema e por floema nas posições adaxial e abaxial. Esses feixes podem aparecer deslocados ou imersos na lâmina e exibir configurações variadas. De acordo com Keating (1984), em Melastomataceae, a forma do sistema vascular da nervura principal encontra-se intimamente relacionada à dimensão das nervuras. Dessa maneira, feixes vasculares planos, arredondados ou em arco determinam nervuras pouco proeminentes, enquanto que feixes de forma cilíndrica ou de semicírculo, em geral, relacionam-se a nervuras proeminentes. Nas espécies aqui estudadas, feixes em arco quase fechado determinam nervuras proeminentes, enquanto que feixes em arco aberto podem estar relacionados tanto com nervuras proeminentes como não proeminentes.

Os feixes vasculares de menor calibre são colaterais e em algumas espécies estes apresentam uma extensão de bainha parenquimática que se prolonga até uma ou as duas superfícies foliares. Dentro da Ordem Myrtales, Keating (1984) observou extensão de bainha parenquimática para poucas espécies de Lythraceae, Trapaceae, Combretaceae e Myrtaceae. Entretanto, Sajo $\&$ Rudall (2002), notaram que dentro de Vochysiaceae, essa característica está presente na maioria dos representantes dos gêneros Erisma, Vochysia, Salvertia, Qualea, Ruizterania e Callisthene
Nos órgãos foliares de Melastomataceae é comum a ocorrência de drusas e de compostos fenólicos, conforme constatado por Costa (1977), Baumgratz \& Ferreira (1980, 1984), Baas (1981), Vecchi (1999) e Souza \& Marquete (2000). Cristais, principalmente drusas, são freqüentes em espécies de Myrtales (Keating 1984, Sajo \& Rudall 2002), bem como compostos fenólicos em Vochysiaceae (Sajo \& Rudall 2002).

Nas folhas de Melastomataceae, o tecido de revestimento mostra-se altamente especializado e variável, podendo muitas vezes caracterizar gêneros. Dessa forma, tricomas tectores são encontrados em Leandra e Miconia (tribo Miconieae), em Microlepsis (tribo Tibouchinieae) e em Microlicia (tribo Microliceae). Entretanto, em Microlicia, os tricomas são simples e bisseriados, em Microlepsis eles são ramificados desde a base, em Leandra os tricomas são dendríticos e em Miconia dendríticos ou ramificados. Nas folhas de Leandra e de Microlepsis, além de tricomas tectores, encontram-se emergências. Emergências também estão presentes nas folhas de Tibouchina (Tribo Tibouchinieae); entretanto, neste gênero não foram observados tricomas tectores de qualquer tipo. Tricomas glandulares estão presentes nas folhas de Microlicia, Tibouchina e Acisanthera. Entretanto, esses tricomas são multisseriados em Acisanthera e unisseridos em Microlicia e Tibouchina, sendo que neste último gênero eles sempre aparecem associados às emergências.

A diversidade dos tricomas em Melastomataceae é relatada por diversos autores (Metcalfe \& Chalk 1950, Souza 1987, Guimarães, Judd 1999) e Wurdack (1986) elaborou um Atlas sobre os tipos encontrados nos representantes neotropicais. De acordo com os tipos apresentados por esse autor, as emergências das Tibouchina aqui estudadas seriam classificadas como "tricomas alongados levemente enrugados" e as emergências e tricomas presentes em Microlepsis como "tricomas dendríticos com eixo bem desenvolvido e vários braços longos", uma vez que Wurdack (1986) não faz distinção entre tricomas e emergências. Os tricomas glandulares, que aparecem nas folhas de Microlicia e associados às emergências em Tibouchina, pertenceriam ao grupo das "glândulas com pedúnculos curtos, cabeça alongada e paredes delgadas" e os de Acisanthera corresponderiam às "glândulas com longos pedúnculos e de cabeça de paredes finas". Em Leandra e na maioria dos representantes de Miconia, os tricomas seriam classificados como "tricomas estrelados pedunculados". 
Já as demais espécies deste último gênero apresentariam "tricomas dendríticos com eixo bem desenvolvido e braços muito longos".

As características anatômicas presentes nas folhas aparentemente não se relacionam ao ambiente onde vivem as espécies, uma vez que é comum para as Melastomataceae em geral a presença de folhas hipostomáticas, tomentosas e recobertas por cutícula espessa. Também é freqüente, nas folhas da família, a presença de hipoderme, de esclereídes, de cristais de oxalato de cálcio e de compostos fenólicos, conforme destacado por Metcalfe \& Chalk (1950), Costa (1977), Baumgratz \& Ferreira (1980), Keating (1984) e Souza $\&$ Marquete (2000).

No presente estudo, foi possível perceber que os aspectos relacionados nas tabelas 1 e 2 são importantes na caracterização dos gêneros estudados. Dessa forma, nota-se que na tribo Miconieae, cutícula ornamentada, epiderme portadora de tricomas tectores, ocorrência de emergências, parênquima paliçádico pouco desenvolvido e feixe vascular principal em forma de arco quase fechado caracterizam as folhas de Leandra. As de Miconia nunca apresentam emergências e, em geral, possuem parênquima paliçádico desenvolvido (50\% ou mais da espessura do mesofilo), além de feixes vasculares da nervura principal, organizados em arco aberto.

Dentro da tribo Tibouchinieae, as folhas de Tibouchina possuem parênquima paliçádico desenvolvido, nervura principal deslocada abaxialmente e emergências associadas a tricomas glandulares. Em Microlepsis também ocorrem emergências epidérmicas, mas os tricomas são tectores e ramificados e o parênquima paliçádico é pouco desenvolvido. Acisanthera apresenta epiderme adaxial desenvolvida e ocasionalmente biestratificada, como observado em outras Myrtales (Ramassamy \& Kannabiran 1996, Sajo \& Rudall 2002); caracteriza-se ainda por apresentar tricomas glandulares multisseriados e mesofilo pouco espesso.

Em Microlicia polysthema (Tribo Microlicieae), as folhas são anfistomáticas, como descrito para Lavoisiera (Souza 1997) que pertence à mesma tribo, e possuem tricomas tectores bisseriados, tricomas glandulares unisseriados e nervura principal, com feixe vascular colateral imerso no mesofilo.

Agradecimentos - As autoras agradecem o suporte financeiro do Projeto Biota - Fapesp (Processo 2000/12469-3). C. dos Reis agradece a bolsa concedida pela Capes.

\section{Referências bibliográficas}

BARROSO, G.M. 1984. Sistemática de Angiospermas do Brasil. Imprensa da Universidade Federal de Viçosa, Viçosa.

BASS, P. 1981. A note on stomatal types and crystals in the leaves of Melastomataceae. Blumea 27: 475-479.

BAUMGRATZ, J.F.A. \& FERREIRA, G.L. 1980. Estudo da nervação e epiderme foliar das Melastomataceae do município do Rio de Janeiro. Gênero Miconia Ruiz et Pavon. Seção Miconia. Rodriguesia 32:61-169.

BAUMGRATZ, J.F.A. \& FERREIRA, G.L. 1984. Estudo da nervação e epiderme foliar das Melastomataceae do município do Rio de Janeiro. Gênero Miconia Ruiz et Pavon. Seção Tamonea (Aubl.) Cogn. Rodriguesia 36:89-94.

BEIGUELMAN, B. 1962a. Contribuição para o estudo anatômico das plantas do cerrado: I. Anatomia da folha e do caule de Erythroxylum suberosum St. Hil. Revista de Biologia 3:97-110.

BEIGUELMAN, B. 1962b. Contribuição para o estudo anatômico das plantas do cerrado: II. Anatomia da folha e do caule de Byrsonima coccolobifolia Kth. Revista de Biologia 3:111-123.

BEIGUELMAN, B. 1962c. Contribuição para o estudo anatômico das plantas do cerrado: III. Anatomia da folha e do caule de Annona coriacea Mart. Revista de Biologia 4:1-12.

BEIGUELMAN, B. 1962d. Contribuição para o estudo anatômico das plantas do cerrado: IV. Anatomia da folha e do caule de Ouratea spectabilis (Mart.) Engl. Revista de Biologia 4:13-26.

BICUDO, L.R.H. 1987. Mapeamento dos cerrados (sensu lato) do município de Botucatu- SP. Florística de duas áreas. Dissertação de mestrado, Universidade Estadual Paulista, Rio Claro.

BICUDO, L.R.H. 1995. Florística, fitossociologia e ciclagem de nutrientes em um cerrado no município de Botucatu, SP. Tese de doutorado, Universidade Estadual Paulista, Rio Claro.

CAVASSAN, O. 1990. Florística e fitossociologia da vegetação lenhosa em um hectare de cerrado no Parque Ecológico Municipal de Bauru (SP). Tese de doutorado, Universidade Estadual de Campinas, Campinas.

COSTA, C.G. 1977. Miconia theaezans (Bomp.) Cogn. (Melastomataceae) considerações anatômicas. Rodriguesia 29:7-92.

CRONQUIST, A.C. 1988. The evolution and classification of flowering plants. The New York Botanical Garden, New York.

FERRACINI, M.C., FERLINI, R.F. \& CAVASSAN, O. 1983. Composição florística de uma área de cerrado no município de Bauru, SP. Salusvita 2:1-9.

FERRI, M.G. 1980. Vegetação brasileira. EDUSP, São Paulo. 
GIANNOTTI, E. 1988. Composição florística e estrutura fitossociológica da vegetação de cerrado e de transição entre cerrado e mata ciliar da Estação Experimental de Itirapina, SP. Dissertação de mestrado, Universidade Estadual de Campinas, Campinas.

GIBBS, P.E., LEITÃO FILHO, H.F. \& SHEPHERD, G. 1983. Floristic composition and community structure in na area of cerrado in SE, Brazil. Flora 173:433-449.

GUIMARÃES, P.J.F., RANGA, N.T. \& MARTINS, A.B. 1999. Morfologia dos tricomas em Tibouchina sect. Pleroma (D. Don.) Cogn. (Melastomataceae). Brazilian Archives of Biology and Tecnology 42:485-493.

HANDRO, W. 1966. Escleromorfismo foliar e nutrição mineral de Gomphrena prostata (Mart.). Anais da Academia Brasileira de Ciências 38:225-242.

HANDRO, W. 1967. Contribuição ao estudo da venação e anatomia foliar das amarantáceas dos cerrados. II Gênero Pfaffia. Anais da Academia Brasileira de Ciências 39:495-506.

HERINGER, E.P., BARROSO, G.M., RIZZO, J.A. \& RIZZINI, C.T. 1977. A flora do cerrado. In: IV Simpósio sobre o cerrado (M.G. Ferri, coord.). Edusp, São Paulo, p.211-232.

HUECK, K. 1978. Los Bosques de Sudamerica. Sociedad Alemania de Cooperación Técnica, Ltda. (GTZ), Eschborn.

JOHANSEN, D.A. 1940. Plant microtechnique. Mac GrawHill, New York.

JOLY, A.B. 1970. Conheça a vegetação brasileira. Edusp, São Paulo.

JUDD, W.S., CAMPBELL, C.S., KELLOGG, E.A. \& STEVENS, P.F. 1999. Plant Systematics. A phylogenetic approach. Massachusetts, Sinauer Associates.

KEATING, R.C. 1984. Leaf histology and its contribution to relationships in the Myrtales. Annals Missouri Botanical Garden 71:801-823.

KRAUS, J.E. \& ARDUIN, M. 1997. Manual básico de métodos em morfologia vegetal. EDUR, Seropédica.

MANTOVANI, W. 1983. Composição e similaridade florística, fenologia e espectro biológico do cerrado da Reserva biológica de Mogi-Guaçu, estado de São Paulo. Dissertação de mestrado, Universidade Estadual de Campinas, Campinas.

MANTOVANI, W. 1987. Análise florística e fitossociológica do estrato esbáceo-subarbustivo do cerrado na Reserva Biológica de Mogi-Guaçu e em Itirapina, SP. Tese de doutorado, Universidade Estadual de Campinas, Campinas.

MEIRA NETO, J.A.A. 1991. Composição florística e fitossociológica da vegetação de cerrado sensu lato da Estação Ecológica de Santa Bárbara, município de Águas de Santa Bárbara, Estado de São Paulo. Dissertação de mestrado, Universidade Estadual de Campinas, Campinas.
MENDONÇA, R.C., FELFILI, J.M., WALTER, B.M.T., SILVA JUNIOR, M.C., REZENDE, A.V., FILGUEIRAS, T.S. \& NOGUEIRA, P.E. 1998. Flora vascular do cerrado. In: Cerrado: ambiente e flora (S.M. Sano \& S.P. Almeida, orgs.). Embrapa-CPA, Planaltina, p. 289-556.

METCALFE, C.R. \& CHALK, L. 1950. Anatomy of the dicotyledons. Claredon Press, Oxford.

MILANEZ, F.R. 1951. Nota sobre a anatomia da folha de Coccoloba cereifera Schwacke. Rodriguesia 14:23-39.

MORRETES, B. L. 1967. Contribuição ao estudo da anatomia das folhas de plantas do cerrado. II. Boletim da Faculdade de Filosofia Ciências e Letras da USP 22:209-244.

MORRETES, B. L. 1969. Contribuição ao estudo da anatomia das folhas de plantas do cerrado. III. Boletim da Faculdade de Filosofia Ciências e Letras da USP 24:209-244.

MORRETES, B. L., \& FERRI, M. G. 1959. Contribuição ao estudo da anatomia das folhas de plantas do cerrado. Boletim da Faculdade de Filosofia Ciências e Letras da USP 24: 7-70.

PAGANO, S. N., CESAR, O \& LEITÃO FILHO, H. F. 1989. Composição florística do estrato arbustivo-arbóreo da vegetação de cerrado da Área de Proteção Ambiental (APA) de Corumbataí - Estado de São Paulo. Revista Brasileira de Biologia 49:37-48.

PANIZA, S. 1967. Contribuição ao estudo morfológico e anatômico de Jacaranda caroba (Velloso) D.C. Bignoniaceae. Revista da Faculdade de Farmácia e Bioquímica da USP 5:93-106.

PAVIANI, T.I. \& FERREIRA, M.L. 1974. Anatomia foliar de Plathymenia reticulata Benth. Revista Brasileira de Biologia 34:159-176.

RAMASSAMY, V. \& KANNABIRAN, B. 1996. Studies on the epidermal and stomatal morfology in transection in some members of Myrtales. Phytomorphology 46:89-97.

RATTER, J.A., RIBEIRO, J.F. \& BRIDGEWATER, S. 1997. The brazilian cerrado vegetation and threats to its biodiversity. Annals of Botany 8:223-230.

RIZZINI, C.T. 1979. Tratado de fitogeografia do Brasil: aspectos sociológicos e florísticos. Edusp, São Paulo.

SAJO, M.G. \& RUDALL, P. 2002. Leaf and stem anatomy of Vochysiaceae in relation to subfamilial systematics. Botanical Journal of the Linnean Society 138:339-364.

SASS, J.E. 1951. Botanical Microtechnique. Iowa State University Press, Ames.

SOUZA, H.C. 1997. Estudo comparativo de adaptações anatômicas em órgãos vegetativos de espécies de Lavoisiera DC. (Melastomataceae) da Serra do Cipó, MG. Tese de doutorado, Universidade de São Paulo, São Paulo.

SOUZA, R.S.O.C. \& MARQUETE, O. 2000. Miconia tristis Spring e Miconia doriana Cogn. (Melastomataceae): anatomia do eixo vegetativo e folhas. Rodriguesia 51:133-142. 
TOLEDO FILHO, D.V. 1984. Composição florística e estrutura fitossociológica da vegetação de cerrado no município de Luís Antônio (SP). Dissertação de mestrado. Universidade Estadual de Campinas, Campinas.

TOLEDO FILHO, D.V., LEITÃOFILHO, H.F. \& RODRIGUES,

T.S. 1984. Composição florística de uma área de cerrado em Mogi-Mirim (SP). Boletim Técnico do Instituto Florestal 8:165-175.
VECCHI, C. 1999. Galha foliar em Tibouchina pulchra (Cham.) Cogn. (Melastomataceae): morfo-anatomia e ontogenia. Dissertação de mestrado, Universidade de São Paulo, São Paulo.

WURDACK, J.J. 1986. Atlas of hair for neotropical Melastomataceae. Smithsonian Contributions to Botany 63:1-80. 